\title{
Aortic valve repair by cusp extension for rheumatic aortic insufficiency in children: Long-term results and impact of extension material
}

\author{
Patrick O. Myers, MD, ${ }^{\text {a,b }}$ Cécile Tissot, MD, ${ }^{\mathrm{c}}$ Jan T. Christenson, MD, ${ }^{\mathrm{a}}$ Mustafa Cikirikcioglu, MD, PhD, ${ }^{\mathrm{a}}$ \\ Yacine Aggoun, $\mathrm{MD}^{\mathrm{c}}$ and Afksendiyos Kalangos, $\mathrm{MD}, \mathrm{PhD}, \mathrm{FECTS}^{\mathrm{a}}$
}

\begin{abstract}
Objective: Aortic valve repair has encouraging midterm results in selected patients. However, neither the longterm results of cusp extension nor the durability of different pericardial fixation techniques has been reported. Our goal was to address these issues.
\end{abstract}

\begin{abstract}
Methods: Seventy-eight children with severe rheumatic aortic regurgitation (mean age $12 \pm 3.5$ years) underwent aortic valve repair using cusp extension over a 15 -year period, with fresh autologous pericardium in $53(67.9 \%)$, glutaraldehyde-fixed bovine pericardium in $9(11.5 \%)$, and PhotoFix bovine pericardium (Sorin CarboMedics, Milano, Italy) in 16 (20.5\%). Fifty-seven children (73.1\%) underwent concomitant mitral valve repair, and 8 children $(10.3 \%)$ underwent tricuspid valve repair.
\end{abstract}

\begin{abstract}
Results: There was 1 operative death from left ventricular failure. During a median follow-up of 10.7 years (range 1 month to 16.4 years), 1 late death occurred and 15 patients (19.7\%) required reoperation at a mean of $43 \pm 33.7$ months (range 1 month to 9 years), 9 within the autologous pericardium group (18\%), 3 within the bovine pericardium group $(33 \%)$, and 3 within the PhotoFix pericardium group (19\%). Freedom from reoperation was $96 \% \pm 2.3 \%$ at 1 year, $87.5 \% \pm 3.9 \%$ at 5 years, $80.7 \% \pm 4.9 \%$ at 10 years, and $75.3 \% \pm 6 \%$ at 15 years, and was significantly decreased in the bovine pericardium group $(P=.039)$. On multivariable analysis, greater age (hazard ratio 1.25, $P<.001$ ) and acute rheumatic carditis (hazard ratio 8.15, $P=.001$ ) at operation were significant predictors of reoperation.
\end{abstract}

Conclusions: Aortic cusp extension provides adequate valve repair in a large proportion of children with rheumatic aortic regurgitation. Fresh autologous and PhotoFix pericardium trended toward better durability than glutaraldehyde-fixed bovine pericardium. (J Thorac Cardiovasc Surg 2010;140:836-44)

\section{Earn CME credits at}

http://cme.ctsnetjournals.org

Surgical management of aortic regurgitation in the young is problematic because of the lack of an ideal valve substitute within this age group. Prosthetic valves carry significant drawbacks, such as difficult lifelong anticoagulation and panus formation for mechanical valves, and rapid deterioration and calcification for biological valves. ${ }^{1}$ Alternate surgical

From the Division of Cardiovascular Surgery, ${ }^{\text {a }}$ Geneva University Hospitals, Geneva, Switzerland; Division of Cardiac Surgery, ${ }^{\mathrm{b}}$ Brigham and Women's Hospital/Harvard Medical School, Boston, Mass; and Pediatric Cardiology Unit, ${ }^{\mathrm{c}}$ Children's Hospital and Geneva University Hospitals, Geneva, Switzerland.

Disclosures: None.

Read at the 90th Annual Meeting of The American Association for Thoracic Surgery, Toronto, Ontario, Canada, May 1-5, 2010.

Received for publication Jan 13, 2010; revisions received March 22, 2010; accepted for publication June 28, 2010; available ahead of print July 26, 2010.

Address for reprints: Patrick O. Myers, MD, Division of Cardiovascular Surgery, Geneva University Hospital and School of Medicine, 4, rue Gabrielle-PerretGentil, 1211 Geneva 14, Switzerland (E-mail: patrick.myers@hcuge.ch). $0022-5223 / \$ 36.00$

Copyright (c) 2010 by The American Association for Thoracic Surgery doi: $10.1016 /$ j.jtcvs. 2010.06 .036 approaches have been used, such as aortic homo- or autograft (Ross procedure) valvular replacement ${ }^{2}$; however, they have not demonstrated their superiority in rheumatic valvular disease. $^{3}$ Rheumatic mitral valve (MV) repair has been shown to be feasible and to have good midterm results. ${ }^{4}$ This has stimulated the development of techniques for aortic valve (AV) repair, which could theoretically result in optimal hemodynamic conditions, avoiding anticoagulation and potentially allowing normal aortic annulus growth. Efforts have been focused on patient selection and subgroups amenable to repair. Duran et $\mathrm{al}^{5}$ developed the cusp extension technique for aortic regurgitation caused by cusp retraction, the most common lesion in rheumatic aortic disease. We previously reported our midterm results with a highly standardized and reproducible modification to the technique, ${ }^{6}$ with actuarial survival of $97 \%$ at 1 and 3 years, exacerbation of aortic regurgitation from grade I to II in only $2.5 \%$ of patients, no significant increase in peak systolic transaortic gradient, and no reoperations for relapsing aortic regurgitation during follow-up. Several midterm reports on the same technique have reported similar results in children, with mean follow-ups of 5.2 years ${ }^{7}$ and 4.6 years, ${ }^{8}$ but no long-term results to this date. Furthermore, differently fixed pericardium has been used, and the results of these different forms of pericardium have not been 

Abbreviations and Acronyms
AI $=$ aortic insufficiency
$\mathrm{AV}=$ aortic valve
$\mathrm{HR}=$ hazard ratio
LVEDD $=$ left ventricular end-diastolic diameter
LVESD $=$ left ventricular end-systolic diameter
$\mathrm{MV}=$ mitral valve

reported. The aim of this study was to update our cohort to report the long-term results of the cusp extension technique for repair of rheumatic aortic regurgitation in children, assess the relative durability of different materials for cusp extension, and identify risk factors for reoperations.

\section{PATIENTS AND METHODS}

The study was reviewed and approved by the local ethics committee, and patient consent was waived.

\section{Demographics}

From March 1993 to July 2007, 78 consecutive children underwent cusp extension AV repair for rheumatic aortic regurgitation caused by cusp retraction. Indications for operation included the presence of grade III or IV aortic insufficiency (AI) resulting in progressive increase in left ventricular dimensions. Eight patients had peak systolic AV gradients greater than 20 $\mathrm{mm} \mathrm{Hg}$. Patient demographics are summarized in Table 1. All of the patients were from African and Asian countries and had a well-documented history of rheumatic fever determined by the revised Jones' criteria. $^{9}$

\section{Operative Procedure}

Our tailored cusp extension technique was previously described in detail and followed rigorously. ${ }^{6}$ All operations were performed by the senior author (A.K.). In 57 patients, concomitant MV repair consisted of annuloplasty and various techniques as reported previously. ${ }^{4}$ After exposing the $\mathrm{AV}$, the cusps were inspected and measured with particular regard to the length of the free edge, the height of the cusps and commissures, and the appearance of the sinuses of Valsalva, aortic annulus, and sinotubular junction. In all patients, tricuspid morphology of the AV was confirmed. No patients had aortic cusp calcification. In 32 patients, a variable degree of cusp thickening and retraction was found with no evidence of cusp prolapse, 17 of whom required cusp shaving. Nine patients underwent concomitant aortic commissurotomy before proceeding to aortic cusp extension. Among the 46 remaining patients, 31 had 1 aortic cusp prolapse with elongation of the free edge and retraction in the height of the cuspal tissue: The noncoronary cusp was prolapsed in 17 patients, the right coronary cusp was prolapsed in 11 patients, and the left coronary cusp prolapsed in 3 patients. Twelve patients had associated right and noncoronary cusp prolapse, 1 patient had right and left coronary cusp prolapse, and 1 patient had prolapse of all 3 cusps. All 3 cusps were extended in all patients.

In 53 patients $(67.9 \%)$, fresh autologous pericardium was used as the cusp extension material. A large rectangular piece of anterior autologous pericardium was cut and applied on a Dacron patch with its mesothelial surface upward. Subsequently, the shape of each pericardial patch was traced onto the Dacron patch, which served as a template for sizing, trimming, and handling of the attached pericardium according to the established dimensions, as described previously. ${ }^{6}$ We used PhotoFix bovine pericardium (CardioFix; Sorin CarboMedics, Milano, Italy) in 16 patients (20.5\%), and then glutaraldehyde-fixed bovine pericardium (St Jude Medical Inc, St Paul, Minn) in 9 patients $(11.5 \%$ ) when Cardiofix was discontinued, in patients who had pericardial adhesions generated by repeated episodes of rheumatic fever and pancarditis. The use of autologous pericardium already affected by inflammatory reaction and fibrosis in these patients was not deemed suitable because of the risk of accelerated structural deterioration. ${ }^{8}$

The cusps were first thinned if their mobility was restricted, maintaining a leathery consistency at cuspal free edges to better hold the sutures. A 5-0 polypropylene suture (Cardionyl; Péters Pharm Lab, Bobigny, France) was passed through the midpoint of the pericardial patch and the corresponding cusp and tied with the knot on the aortic side. Each arm of the tied suture was run up to the commissures and tied with the suture from the neighboring cusp over a pericardial pledget outside the aorta. The Dacron patch was then removed. The same procedure was repeated for each cusp with each specifically corresponding scalloped pericardial patch.

When required, tricuspid annuloplasty was performed on a beating heart after other valvar procedures were finished. Intraoperative transesophageal echocardiography examinations were performed in all patients before skin incision and after termination of cardiopulmonary bypass.

\section{Follow-up}

Transthoracic echocardiography was carried out in all patients before surgery, before discharge from the hospital, and at 3 and 6 weeks postoperatively in the outpatient clinic of the Geneva University Hospitals before returning to their countries of origin.

Doppler echocardiographic grade of AI was measured with color Doppler flow and graded from the width and length of the regurgitant jet in the left ventricle (grade $0-$ IV) according to previously described criteria. ${ }^{10}$ Peak gradient across the AV was estimated by measuring peak systolic velocity from Doppler studies in the transthoracic 5-chamber or suprasternal notch sagittal view. Left ventricular end-diastolic diameter (LVEDD), left ventricular end-systolic diameter (LVESD), and left ventricular shortening fraction were measured at midpapillary level in the standardized parasternal transthoracic long- or short-axis position. Z-scores were calculated using the latest formulas. ${ }^{11}$ Seventy-six of the 78 patients $(97 \%)$ were thereafter followed in outpatient clinics by cardiologists in their country of origin, who periodically informed us of the patients' evolution by filling out a questionnaire, including clinical, echocardiographic, and medication information. Follow-up in this study was achieved until July 2009. We followed published guidelines in reporting freedom from valve-related events. ${ }^{12}$

\section{Statistical Analysis}

Statistical analyses were performed with the Statistical Package for the Social Sciences (SPSS Inc, Chicago, Ill). Data are presented as mean \pm standard deviation. Continuous variables were analyzed with the Student $t$ test or the related samples Wilcoxon signed-rank test when appropriate, and categoric variables were analyzed with the chi-square test. Differences between cusp extension material group continuous variables were analyzed with analysis of variance with Bonferroni post hoc correction. Actuarial estimates were calculated using the Kaplan-Meier method, and differences between curves were assessed by the log-rank test. Univariate and stepwise Cox multivariable regression analyses were used to identify the independent predictors of late outcomes. Preoperative and operative variables with a univariate $P$ less than .1 or those judged to be clinically important were entered into the Cox models. Hazards ratios for reoperation of risk factors were calculated using univariate and multivariable Cox proportional hazards estimates. All statistical tests were 2-tailed. Methodological support was provided by the Clinica Research Center, University of Geneva, and Geneva University Hospitals.

\section{RESULTS}

\section{Early Outcome}

The mean aortic crossclamping time was $73.9 \pm 35.2$ minutes (range, 33-144 minutes) for 21 children undergoing isolated AV repair and 112.1 \pm 34.7 minutes (range 58-195 minutes) for 57 children undergoing concomitant MV and 
TABLE 1. Patient characteristics

\begin{tabular}{|c|c|c|c|c|c|}
\hline Variable & $\begin{array}{l}\text { Entire study } \\
\text { population } \\
N=78\end{array}$ & $\begin{array}{c}\text { Fresh autologous } \\
\text { pericardium } \\
\mathbf{n}=\mathbf{5 3}\end{array}$ & $\begin{array}{l}\text { Glutaraldehyde-fixed } \\
\text { bovine pericardium } \\
\qquad \mathbf{n}=\mathbf{9}\end{array}$ & $\begin{array}{c}\text { PhotoFix (Sorin CarboMedics, } \\
\text { Milano, Italy) bovine pericardium } \\
n=16\end{array}$ & $P$ \\
\hline Age (y) & $12.3 \pm 3.5$ & $11.9 \pm 2.7$ & $14.5 \pm 8.9$ & $12.4 \pm 2.8$ & $.24 \dagger$ \\
\hline Male & $49(63 \%)$ & $33(62 \%)$ & $5(56 \%)$ & $11(69 \%)$ & $.80 \ddagger$ \\
\hline Weight & $33.4 \pm 9.6 \mathrm{~kg}$ & $33.1 \pm 10.0 \mathrm{~kg}$ & $47.0 \pm 12.5 \mathrm{~kg}$ & $32.4 \pm 7.6 \mathrm{~kg}$ & $.36 \dagger$ \\
\hline Acute rheumatic carditis* & $4(5 \%)$ & $2(3.8 \%)$ & $1(11.1 \%)$ & $1(6.3 \%)$ & $.65 \ddagger$ \\
\hline \multicolumn{6}{|l|}{ NYHA functional class } \\
\hline I or II & $5(6.4 \%)$ & $3(5.7 \%)$ & $1(11.1 \%)$ & $1(6.3 \%)$ & $.83 \ddagger$ \\
\hline III or IV & $73(93.6 \%)$ & $50(94.3 \%)$ & $8(88.9 \%)$ & $15(93.8 \%)$ & $.83 \ddagger$ \\
\hline \multicolumn{6}{|l|}{ Concomitant surgery } \\
\hline Mitral valve repair & $57(73 \%)$ & $40(75.5 \%)$ & $5(55.6 \%)$ & $12(75 \%)$ & $.45 \ddagger$ \\
\hline Tricuspid valve repair & $8(10 \%)$ & $5(9.4 \%)$ & $0(0 \%)$ & $3(18.8 \%)$ & $.31 \ddagger$ \\
\hline
\end{tabular}

NYHA, New York Heart Association. *Active rheumatic carditis was based on clinical examination, serologic criteria, and surgical macroscopic evaluation. $\dagger$ One-way analysis of variance. $\ddagger$ Chi-square test.

AV repair. There was 1 operative death from left ventricular failure. Two patients presented intraoperative suspected dynamic coronary ostia occlusion by the extension patches after crossclamp removal (evidenced by intractable ventricular fibrillation), requiring cardioplegic arrest, valve repair exploration, and shortening of each cusp extension patch by $1 \mathrm{~mm}$. Both patients subsequently regained normal sinus rhythm and had an uneventful postoperative course.

\section{Late Outcome}

Follow-up was complete in $98.7 \%$ of the patients (76/77). The patient lost to follow-up was from the early part of the series. Mean and median follow-ups were $115.5 \pm 61.4$ months and 128 months, respectively, ranging from 1 to 16.4 years overall. The median follow-up for the fresh autol-

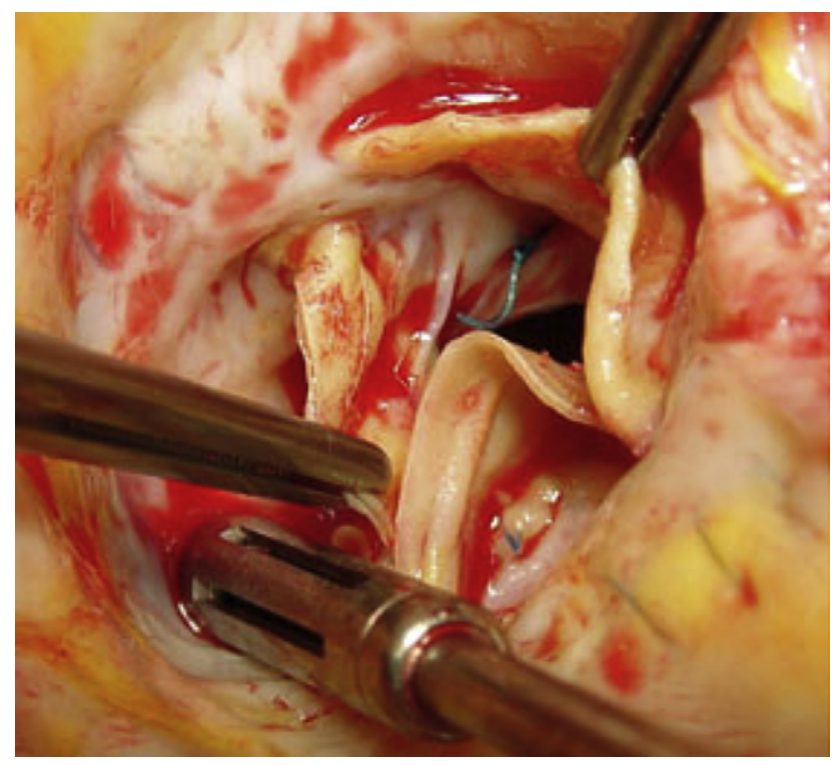

FIGURE 1. PhotoFix pericardium cusp extension 5 years later. Surgical view of the repaired $\mathrm{AV}$ in a patient requiring reoperation for MV repair 5 years after PhotoFix (Sorin CarboMedics, Milano, Italy) cusp extension. The extensions were pliable and presented no calcifications or retraction. ogous pericardium group was 163 months (mean, $142 \pm$ 54.9 months), 22 months for the bovine pericardium group (mean, $43 \pm 38$ months), and 75.5 months for the PhotoFix pericardium group (mean, $71.7 \pm 21.3$ months). One patient died of sudden cardiac arrhythmia at home in the 55th postoperative month, with apparently competent $\mathrm{AV}$ and MV. In all patients, anticoagulation with warfarin began on the second postoperative day and was stopped during the third postoperative month until 1999; since then, patients did not receive any anticoagulation unless another indication required it. No thromboembolic or hemorrhagic events were observed up to the most recent follow-up examinations. Fifteen patients $(19.7 \%)$ underwent reoperation for severe $\mathrm{AV}$ dysfunction after a mean period of $42.9 \pm 33.7$ months (range, 1.2-108 months) from the initial AV repair, 9 within the autologous pericardium group $(18 \%), 3$ within the glutaraldehyde pericardium group ( $33 \%$ ), and 3 within the PhotoFix pericardium group $(19 \%)$.

The mode of failure differed depending on the extension material: Glutaraldehyde-fixed bovine pericardium presented deterioration from calcification; fresh autologous pericardium underwent inflammatory cell infiltration and a variable degree of retraction; PhotoFix pericardium was surprisingly unaffected (Figure 1), and repair failure was linked to continued rheumatic degeneration of the native leaflets or annular dilatation.

Among the 15 patients requiring reoperation for AV replacement, 3 required concomitant MV replacement. Two more patients required non-AV-related reoperation during follow-up, 1 for MV replacement and 1 for MV repair.

\section{Valve Function}

Of the 76 patients followed up, 44 (58\%) had no or trivial AV regurgitation and 14 (18\%) showed mild aortic regurgitation at their last follow-up echocardiography. Eighteen patients $(24 \%)$ had significant aortic regurgitation during follow-up. The aortic regurgitation was moderate to severe (grade III) in 7 patients (9\%) and severe (grade IV) in 11 


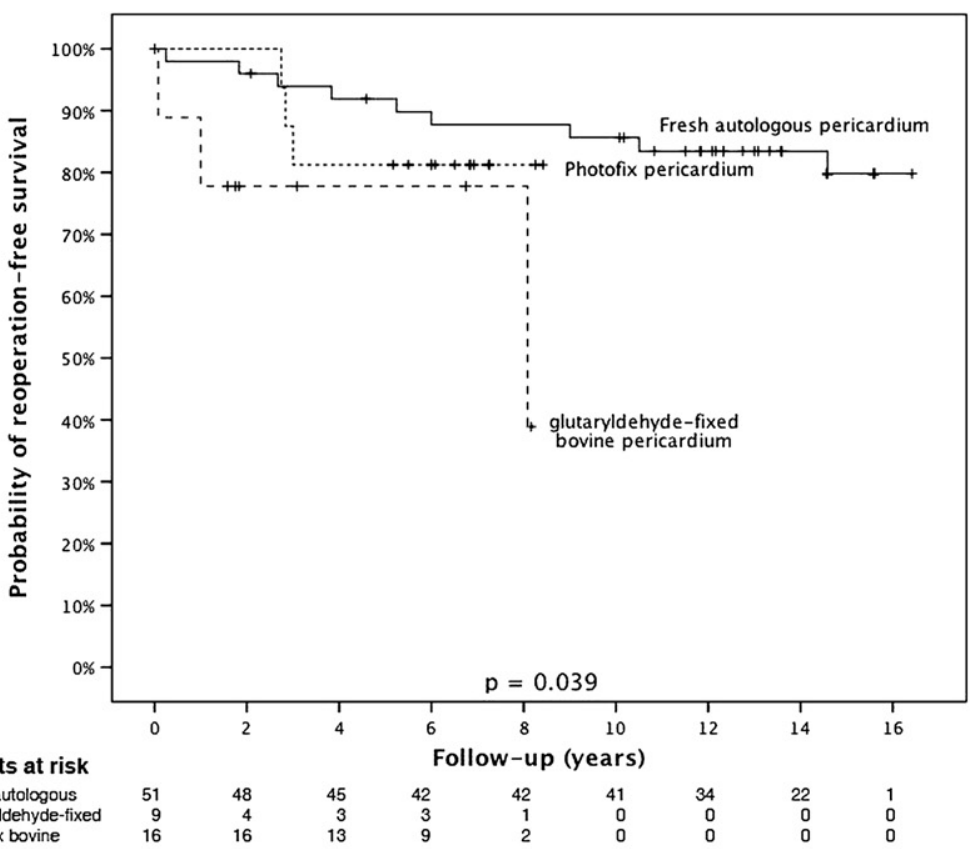

A

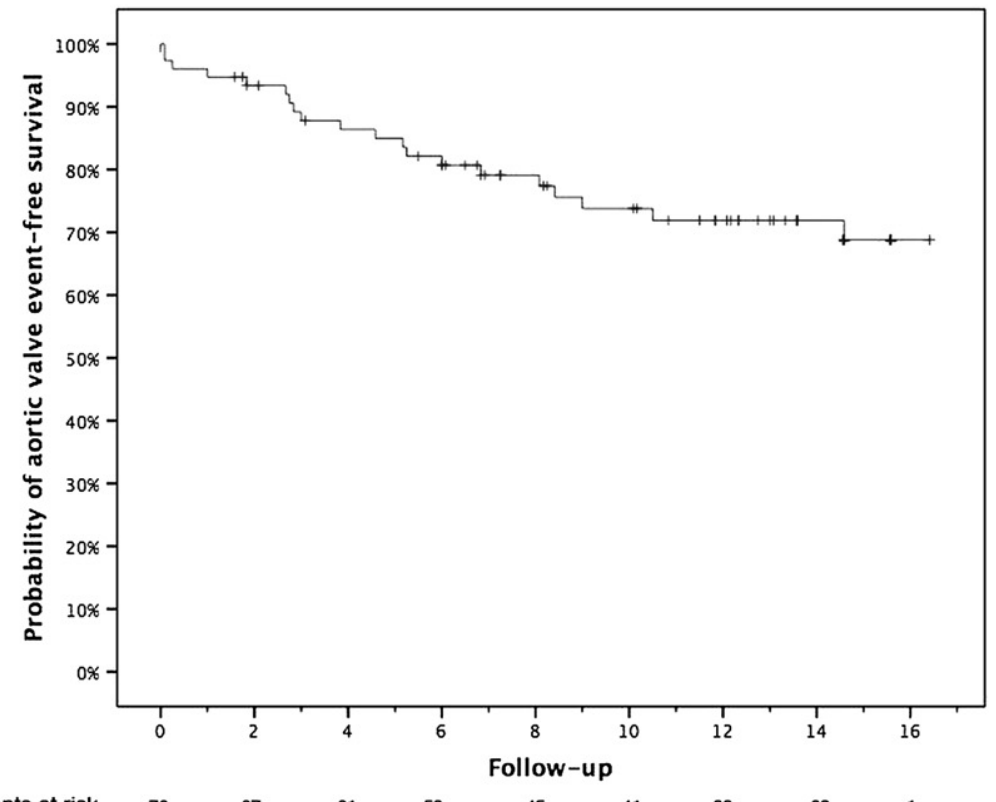

B

FIGURE 2. Survival curves after AV repair for rheumatic AV regurgitation in 78 children. A, Actuarial freedom from reoperation-free survival. B, Actuarial freedom from AV-related event-free survival (including early and late deaths, reoperation, moderate to severe aortic regurgitation, endocarditis, and thromboembolism).

patients $(15 \%)$. The 11 patients with severe aortic regurgitation and 4 patients with grade III aortic regurgitation all underwent reoperation. The remaining 3 patients with grade III regurgitation are being monitored, and 1 patient is scheduled for reoperation.

Actuarial freedom from reoperation for significant aortic regurgitation was $96 \% \pm 2.3 \%$ at 1 year, $87.5 \% \pm 3.9 \%$ at 5 years, $84.6 \% \pm 4.3 \%$ at 7 years, $80.7 \% \pm 4.9 \%$ at 10 years, $78.7 \% \pm 5.2 \%$ at 12 years, and $75.3 \% \pm 6 \%$ at 15 years. For the fresh autologous pericardium group, freedom from reoperation was $98 \% \pm 2 \%$ at 1 year, $91.9 \% \pm 3.9 \%$ at 5 years, $83.5 \% \pm 5.4 \%$ at 10 years, and $79.8 \% \pm 6.2 \%$ at 15 years. For the glutaraldehyde-fixed bovine pericardium group, freedom from reoperation was $88.9 \% \pm 10.5 \%$ at 1 year, 
TABLE 2. Cox regression analysis of predictors for reoperation

\begin{tabular}{|c|c|c|c|c|c|c|}
\hline \multirow[b]{2}{*}{ Variable } & \multicolumn{3}{|c|}{ Univariable } & \multicolumn{3}{|c|}{ Multivariable } \\
\hline & HR & $\boldsymbol{P}$ & $95 \%$ CI & HR & $\boldsymbol{P}$ & $95 \% \mathrm{CI}$ \\
\hline Age & 1.24 & $<.001$ & $1.10-1.39$ & 1.25 & $<.001$ & $1.10-1.40$ \\
\hline Male gender & 0.57 & .28 & $0.20-1.59$ & 1.25 & .70 & $0.41-3.86$ \\
\hline Concomitant mitral operation & 1.59 & .48 & $0.45-5.62$ & 1.21 & .81 & $0.09-54.29$ \\
\hline Concomitant tricuspid operation & 2.25 & .21 & $0.63-7.99$ & 2.45 & .16 & $0.69-9.35$ \\
\hline Acute rheumatic carditis & 9.57 & $<.001$ & $2.92-31.35$ & 8.15 & .001 & $2.45-27.11$ \\
\hline Extension material & & .07 & & & .78 & \\
\hline Fresh autologous pericardium* & 1 & & & 1 & & \\
\hline Glutaraldehyde-fixed bovine pericardium & 5.31 & .02 & $1.30-21.66$ & 2.01 & .49 & $0.28-14.52$ \\
\hline PhotoFix bovine pericardium & 1.81 & .41 & $0.44-7.35$ & 1.11 & .90 & $0.23-5.38$ \\
\hline Aortic commissurotomy & 8.19 & .007 & $1.78-37.62$ & 0.89 & .94 & $0.04-19.83$ \\
\hline
\end{tabular}

HR, Hazard ratio; $C I$, confidence interval. *Reference group.

$77.8 \% \pm 13.9 \%$ at 5 years, and $77.8 \% \pm 13.9 \%$ at 8 years. For the PhotoFix pericardium group, freedom from reoperation was $93.8 \% \pm 6.1 \%$ at 1 year, $81.3 \% \pm 9.8 \%$ at 5 years, and $81.3 \% \pm 9.8 \%$ at 7 years. This difference was statistically significant, with a higher reoperation rate in the bovine pericardium group (log-rank test, $P=.039$; Figure $2, A$ ). On univariate analysis, greater age (hazard ratio $[\mathrm{HR}] 1.24, P<.001$ ), acute rheumatic carditis (HR 9.57, $P<.001$ ) at operation, necessity of aortic commissurotomy before cusp extension (HR $8.19, P=.007$ ), and use of glutaraldehyde pericardium (HR $5.31, P=.02$ ) were predictors of reoperation (Table 2). On multivariable analysis, only greater age and acute rheumatic carditis at operation were significant independent predictors of reoperation.

AV-related event-free survival (including death, reoperation, and moderate to severe aortic regurgitation) was $85 \% \pm 4.2 \%$ at 5 years, $73.8 \% \pm 5.4 \%$ at 10 years, and $68.8 \% \pm 6.1 \%$ at 15 years after the initial operation (Figure 2, B).

TABLE 3. Transvalvular gradients

\begin{tabular}{lccc}
\hline \multicolumn{1}{c}{ Variable } & $\begin{array}{c}\text { Fresh } \\
\text { autologous } \\
\text { pericardium }\end{array}$ & $\begin{array}{c}\text { Glutaraldehyde-fixed } \\
\text { bovine pericardium }\end{array}$ & $\begin{array}{c}\text { PhotoFix } \\
\text { pericardium }\end{array}$ \\
\hline Preoperative & $17.2 \pm 5.0$ & $19.4 \pm 6.8$ & $17.5 \pm 7.2$ \\
Discharge & $16.0 \pm 5.5$ & $15.7 \pm 4.8$ & $14.4 \pm 6.9$ \\
$P^{*}$ & .04 & .007 & .003 \\
Latest follow-up & $22.1 \pm 8.6$ & $19.9 \pm 5.7$ & $21.9 \pm 13.7$ \\
$P \dagger$ & $<.001$ & .03 & .009 \\
Increase per year & $1.0 \pm 2.4$ & $3.6 \pm 3.7$ & $1.1 \pm 2.4$ \\
$P \ddagger$ & $*$ & .02 & 1.0 \\
\hline
\end{tabular}

$* P$ value: comparison between the preoperative values versus those at discharge within each treatment group using related samples Wilcoxon signed-rank test. $\dagger P$ value: comparison between the values at discharge versus those at latest follow-up within each treatment group using related samples Wilcoxon signed-rank test. $\ddagger P$ value: comparison between the increase in peak transvalvular gradient per year, compared with the reference group $(*)$ using analysis of variance multiple comparisons with Bonferroni post hoc comparison. Overall analysis of variance test of significance was $P=.02$. All values are reported as mean \pm standard deviation, in millimeters of mercury unless otherwise noted.

\section{Transvalvular Gradients}

The peak gradients through the AV are shown in Table 3. There was a significant increase in the peak gradient during follow-up, from a mean postoperative value of $15.6 \pm 5.7$ $\mathrm{mm} \mathrm{Hg}$ to a mean of $21.8 \pm 9.5 \mathrm{~mm} \mathrm{Hg}$ at the latest follow-up $(P<.001)$, regardless of the material used for cusp extension. This represented an increase of $6.3 \pm 9.3 \mathrm{~mm} \mathrm{Hg}$, or $1.3 \pm 2.7 \mathrm{~mm} \mathrm{Hg} / \mathrm{y}$, during followup, which was markedly increased in the bovine pericardium group $(3.6 \pm 3.7 \mathrm{~mm} \mathrm{Hg} / \mathrm{y}, P=.02)$.

\section{Left Ventricular Dimensions and Shortening Fraction}

Increased preload caused by aortic regurgitation resulted in enlarged LVEDD and LVESD values preoperatively of $6.1 \pm 0.6 \mathrm{~cm}$ (z-score $4.1 \pm 1.1)$ and $4.0 \pm 0.5 \mathrm{~cm}$ (z-score $3.6 \pm 1.0)$, respectively. Mean LVEDD and LVESD were significantly $(P<.001)$ reduced at hospital discharge: $4.7 \pm 0.5 \mathrm{~cm}$ (z-score $1.5 \pm 1.3$ ) and $3.6 \pm 0.6 \mathrm{~cm}$ (z-score $2.9 \pm 1.2$ ), respectively. These values increased at latest follow-up to $4.9 \pm 0.5 \mathrm{~cm}$ (z-score $2.3 \pm 2.2$ ) and $3.4 \pm$ 0.5 (z-score $2.7 \pm 1.8$ ), respectively; these are significantly increased when comparing discharge with follow-up LVEDD and LVESD values $(P<.001$ for both) and LVEDD z-scores $(P=.008)$, but not when comparing discharge and follow-up values indexed to body surface area $(P=.06$ and .5 , respectively) and z-scores $(P=.48)$. By comparing the different cusp extension material groups, there was no significant difference between their respective preoperative $(P=.37$ and .29$)$, discharge $(P=.72$ and .51$)$, and follow-up ( $P=.29$ and .73 , respectively) LVEDD and LVESD values. Comparison of indexed values and z-scores did not demonstrate any more significant differences between groups.

The mean preoperative left ventricular shortening fraction was $34.4 \% \pm 3.3 \%$, followed by a significant reduction $(P<.001)$ at the time of hospital discharge to $23.5 \% \pm$ $4.3 \%$, and followed by a significant increase $(P<.001)$ at 
latest follow-up to $30.6 \% \pm 4.1 \%$. There were no significant differences between cusp extension material groups at each time point ( $P=.58, .17$, and .24 respectively).

\section{DISCUSSION}

Long-term results in surgery for mitral regurgitation have demonstrated that repair is advantageous over replacement in terms of survival and incidence of thromboembolic and bleeding complications. ${ }^{13} \mathrm{MV}$ repair has thus become the treatment of choice, and its feasibility has led to the recommendation of earlier surgery, even in asymptomatic patients, to preserve ventricular geometry and function. ${ }^{14}$ Part of these advances has come from better understanding the causes and specific mechanisms of mitral regurgitation and identification of patient subgroups and the optimal repair technique to be applied. A major limitation to the more generalized application of AV repair is the absence of such a common framework for valve assessment to guide the approach to valve repair. Boodhwani and colleagues ${ }^{15}$ proposed a repair-oriented functional nomenclature, similar to Carpentier's pioneering classification of mitral regurgitation, ${ }^{16}$ dividing lesions into 3 types: I (mainly due to aortic dilatation), II (cusp prolapse), and III (cusp retraction). Various series have reported encouraging midterm outcomes in heterogeneous groups of patients undergoing $\mathrm{AV}$ repair. Aicher and colleagues ${ }^{17}$ reviewed their experience in 640 patients (mean age, $56 \pm 17$ years) undergoing AV repair for insufficiency of all functional types and causes, with freedom from reoperation at 5 and 10 years of $88 \%$ and $81 \%$ for bicuspid valves and $97 \%$ and $93 \%$ in tricuspid valves, respectively. Boodhwani and colleagues ${ }^{15}$ reported 264 patients (median age, 55 years) with a 5-year survival of $95 \% \pm$ $3 \%$ and freedom from reoperation of $92 \% \pm 4 \%$. However, freedom from reoperation was reduced in restricted (type III) AVs $(88 \% \pm 9 \%$ vs $94 \% \pm 4 \%$ in types I and II, $P=.08)$, and freedom from recurrent AI greater than 2 was significantly lower for type III lesions than for type I or II lesions (HR 2.6; 95\% confidence interval, 1.1-11.6; $P=.03$ ). These results are encouraging for a more widespread use of AV repair. Nonetheless, specific subgroups of patients and their optimal repair strategy need to be assessed. Furthermore, these results must be confirmed in children. In practically the only study in children, Bacha and colleagues ${ }^{18}$ reported 81 patients (median age, 8.6 years) with aortic regurgitation from congenital causes, after balloon valvuloplasty or other interventions, and a minority of rheumatic and endocarditic causes, with estimated freedom from AV replacement of $72 \% \pm 6 \%$ at 5 years and $54 \% \pm 9 \%$ at 7.5 years, with a significant decrease in left ventricular dimensions, showing that surgical aortic valvuloplasty is a valid option with good intermediate results for children and adolescents with aortic regurgitation from a variety of causes.

We have focused our attention on patients with aortic regurgitation caused by cusp retraction, the most common lesion in rheumatic aortic disease. We previously reported our short and midterm results ${ }^{6}$ in 49 children (mean age, $11.5 \pm 2.7$ years), with an actuarial survival of $97 \%$ at 3 years and no reoperations, and showed growth of the repaired valves with no increase in peak systolic gradients during follow-up. Grinda and colleagues ${ }^{8}$ reported 89 patients (mean age, $16 \pm 5$ years) who underwent cusp extension for rheumatic AV disease. Five-year survival and freedom from aortic reoperation were $96 \%$ and $92 \%$, respectively. Bozbuga and colleagues ${ }^{7}$ reported 46 patients with rheumatic valve disease (mean age, $35 \pm 12$ years) with survival of $98 \%$ at 8.6 years and freedom from reoperation of $76.1 \%$ at 7.5 years. The longest available results with this technique, with a follow-up of up to 16 years, were reported by $\mathrm{Al}$ Halees and colleagues ${ }^{19}$ for 92 patients (mean age, 30 years) with mostly rheumatic valve disease. The survival was $85 \%$. There were no episodes of thromboembolism, and freedom from reoperation was $68 \%$ at 10 years and $47 \%$ at 16 years. We report significantly improved results with our tailored, highly standardized modification to triple cusp extension repair, with freedom from reoperation of $81 \% \pm 5 \%$ at 10 years and $75 \% \pm 6 \%$ at 15 years.

Various materials have been used to extend the aortic cusps, including fascia lata, ${ }^{20}$ heterologous (bovine) pericardium, ${ }^{19}$ fresh autologous pericardium, ${ }^{6}$ and glutaraldehydestabilized autologous pericardium. ${ }^{8,21}$ Duran and colleagues $^{5,22}$ compared the use of glutaraldehyde-fixed bovine and autologous pericardium. At the short to midterm, ${ }^{5,22}$ bovine pericardium seemed to have significantly worse outcomes, making them abandon this material for cusp extension. At long-term follow-up, however, there was no significant difference between the groups, with freedom from reoperation of $72 \% \pm 6 \%$ at 10 years and $45 \% \pm$ $8 \%$ at 16 years in the bovine pericardium group versus $68 \% \pm 5 \%$ at 10 years and $47 \% \pm 6 \%$ at 16 years in the fresh autologous pericardium group. ${ }^{19}$ We confirm the initial results of Duran and colleagues, ${ }^{5,22}$ with significantly worse results with glutaraldehyde-fixed bovine pericardium at the midterm, with freedom from reoperation of $78 \% \pm 14 \%$ at 7 years compared with $85 \% \pm 4 \%$ for fresh autologous pericardium and $81 \% \pm 10 \%$ for PhotoFix bovine pericardium. However, these results must be mitigated, because the statistical significance of the log-rank analysis is limited by the number of events and reaches significance based on a single supplementary event in the glutaraldehyde pericardium group; furthermore, this trend was not confirmed on multivariable analysis. The multivariable models used are also limited by the number of events: There are 15 events for $8 \mathrm{de}$ grees of freedom in the model (Table 2), although 5 to 10 times more events than degrees of freedom are usually recommended. Finally, the comparison of the rate of increase of transvalvular gradients between the groups is confounded by the relatively short follow-up in the glutaraldehyde pericardium group relative to the other groups. 
Despite these limitations, PhotoFix pericardium trended to be the better alternative in patients in whom autologous tissue cannot be used. PhotoFix is an alternative to glutaraldehyde fixation, which uses dye-mediated photo-oxidation rather than chemical cross-linking. Photo-oxidized bovine pericardium is similar to untreated tissue in texture, pliability, and shrinkage temperature, but unlike untreated tissue, it possesses chemical, enzymatic, and in vivo stability. It is thus non-immunogenic, biocompatible, and, unlike glutaraldehyde-treated tissues, noncalcifying and noncytotoxic, thus allowing endothelization. ${ }^{23}$ Its use in valve reconstruction has been limited ${ }^{24}$ because of poor results with PhotoFix-based bioprostheses, ${ }^{25}$ although this was shown to be due to valve design rather than fixation technique.

\section{Study Limitations}

This study has several limitations. It is a retrospective and nonrandomized comparison of aortic cusp extension materials and represents a 15-year period of evolving experience with AV repair. As such, any inferences drawn from these data are limited by confounding variables, such as extent of cusp disease, severity of preoperative AI, need for MV or tricuspid repair, and duration of follow-up, which are differently distributed between study groups. Our sample size also limits our ability to perform extensive statistical adjustments for these differences. Finally, follow-up echocardiographic data were interpreted and analyzed, for the most part, by the referring cardiologist in the patients' country of origin. This introduces the risk of estimator bias, because the echocardiographic images could not be interpreted by an independent echocardiography laboratory blinded to the surgery, extension material, and clinical outcome.

\section{CONCLUSIONS}

Aortic cusp extension provides adequate valve repair in a large proportion of children with rheumatic aortic regurgitation. Fresh autologous and PhotoFix bovine pericardium showed better durability, requiring fewer reoperations than glutaraldehyde pericardium at midterm.

\section{References}

1. Walker WE, Duncan JM, Frazier OH Jr, Livesay JJ, Ott DA, Reul GJ, et al. Early experience with the ionescu-shiley pericardial xenograft valve. Accelerated calcification in children. J Thorac Cardiovasc Surg. 1983;86:570-5.

2. Gerosa G, McKay R, Davies J, Ross DN. Comparison of the aortic homograft and the pulmonary autograft for aortic valve or root replacement in children. J Thorac Cardiovasc Surg. 1991;102:51-61.

3. Choudhary SK, Mathur A, Sharma R, Saxena A, Chopra P, Roy R, et al. Pulmonary autograft: should it be used in young patients with rheumatic disease? J Thorac Cardiovasc Surg. 1999;118:483-91.

4. Kalangos A, Christenson JT, Beghetti M, Cikirikcioglu M, Kamentsidis D, Aggoun Y. Mitral valve repair for rheumatic valve disease in children: midterm results and impact of the use of a biodegradable mitral ring. Ann Thorac Surg. 2008;86:161-9.

5. Duran C, Kumar N, Gometza B, al Halees Z. Indications and limitations of aortic valve reconstruction. Ann Thorac Surg. 1991;52:447-54.

6. Kalangos A, Beghetti M, Baldovinos A, Vala D, Bichel T, Mermillod B, et al. Aortic valve repair by cusp extension with the use of fresh autologous pericardium in children with rheumatic aortic insufficiency. J Thorac Cardiovasc Surg. 1999; 118:225-36.

7. Bozbuga N, Erentug V, Kirali K, Akinci E, Isik O, Yakut C. Midterm results of aortic valve repair with the pericardial cusp extension technique in rheumatic valve disease. Ann Thorac Surg. 2004;77:1272-6.

8. Grinda JM, Latremouille C, Berrebi AJ, Zegdi R, Chauvaud S, Carpentier AF, et al. Aortic cusp extension valvuloplasty for rheumatic aortic valve disease: midterm results. Ann Thorac Surg. 2002;74:438-43.

9. Jones Criteria (revised) for guidance in the diagnosis of rheumatic fever. Circulation. 1984;69:204A-8.

10. Perry GJ, Helmcke F, Nanda NC, Byard C, Soto B. Evaluation of aortic insufficiency by Doppler color flow mapping. J Am Coll Cardiol. 1987;9:952-9.

11. Pettersen MD, Du W, Skeens ME, Humes RA. Regression equations for calculation of $\mathrm{z}$ scores of cardiac structures in a large cohort of healthy infants, children, and adolescents: an echocardiographic study. J Am Soc Echocardiogr. 2008;21:922-34.

12. Akins CW, Miller DC, Turina MI, Kouchoukos NT, Blackstone EH, Grunkemeier GL, et al. Guidelines for reporting mortality and morbidity after cardiac valve interventions. J Thorac Cardiovasc Surg. 2008;135:732-8.

13. Mohty D, Orszulak TA, Schaff HV, Avierinos JF, Tajik JA, Enriquez-Sarano M. Very long-term survival and durability of mitral valve repair for mitral valve prolapse. Circulation. 2001;104(12 Suppl. 1):I1-7.

14. Bonow RO, Carabello BA, Chatterjee K, de Leon AC Jr, Faxon DP, Freed MD, et al. 2008 Focused update incorporated into the ACC/AHA 2006 guidelines for the management of patients with valvular heart disease: a report of the American College of Cardiology/American Heart Association Task Force on Practice Guidelines (Writing Committee to Revise the 1998 Guidelines for the Management of Patients With Valvular Heart Disease): endorsed by the Society of Cardiovascular Anesthesiologists, Society for Cardiovascular Angiography and Interventions, and Society of Thoracic Surgeons. Circulation. 2008;118:e523-661.

15. Boodhwani M, de Kerchove L, Glineur D, Poncelet A, Rubay J, Astarci P, et al. Repair-oriented classification of aortic insufficiency: impact on surgical techniques and clinical outcomes. J Thorac Cardiovasc Surg. 2009;137:286-94.

16. Carpentier A. Cardiac valve surgery-the "French correction'" J Thorac Cardiovasc Surg. 1983;86:323-37.

17. Aicher D, Fries R, Rodionycheva S, Schmidt K, Langer F, Schäfers HJ. Aortic valve repair leads to a low incidence of valve-related complications. Eur J Cardiothorac Surg. 2010;37:127-32.

18. Bacha EA, McElhinney DB, Guleserian KJ, Colan SD, Jonas RA, del Nido PJ, et al. Surgical aortic valvuloplasty in children and adolescents with aortic regurgitation: acute and intermediate effects on aortic valve function and left ventricular dimensions. J Thorac Cardiovasc Surg. 2008;135:552-9, 9 e1-3.

19. Al Halees Z, Al Shahid M, Al Sanei A, Sallehuddin A, Duran C. Up to 16 years follow-up of aortic valve reconstruction with pericardium: a stentless readily available cheap valve? Eur J Cardiothorac Surg. 2005;28:200-5.

20. Senning A, Rothlin M. The late fate of autologous fascia lata valve grafts in the aortic position. Isr J Med Sci. 1975;11:179-84.

21. Alsoufi B, Karamlou T, Bradley T, Williams WG, Van Arsdell GS, Coles JG, et al. Short and midterm results of aortic valve cusp extension in the treatment of children with congenital aortic valve disease. Ann Thorac Surg. 2006;82:1292-300.

22. Duran C, Gometza B, Shahid M, al Halees Z. Treated bovine and autologous pericardium for aortic valve reconstruction. Ann Thorac Surg. 1988;66:S166-9.

23. Schmidt CE, Baier JM. Acellular vascular tissues: natural biomaterials for tissue repair and tissue engineering. Biomaterials. 2000;21:2215-31.

24. Verbrugghe P, Meuris B, Flameng W, Herijgers P. Reconstruction of atrioventricular valves with photo-oxidized bovine pericardium. Interact Cardiovasc Thorac Surg. 2009;9:775-9.

25. Schoen FJ. Pathologic findings in explanted clinical bioprosthetic valves fabricated from photooxidized bovine pericardium. J Heart Valve Dis. 1998;7:174-9.

\section{Discussion}

Dr Emile Bacha (New York, NY). Although retrospective, this is an important article for the following reasons: It comes from a center with a large experience with AV repair, thus having digested the learning curve. It reports on a homogeneous group of patients, all of whom had rheumatic fever. It focuses on patch material, something that hasn't been done really in the past series.

It seems to me that $\mathrm{AV}$ repair as a technique is maturing and much less controversial. However, it's remarkable to note that 
outcomes remain kind of stuck at $20 \%$ to $30 \%$ reoperation rate and roughly $70 \%$ freedom from reoperation at 7 to 10 years. Thus, there is still a lot of room for improvement, and one improvement could come from better patch material. I have a few questions. Please confirm your current choice of patch material at this point in time.

Dr Myers. Fresh autologous pericardium.

Dr Bacha. What will be your second choice if the pericardium is involved with the rheumatic carditis?

Dr Myers If it were available, we would use PhotoFix pericardium because in our experience it doesn't calcify or retract, and it stays pretty much as is during its life. So that would be our second choice if it's not possible to use autologous pericardium.

Dr Bacha. Because it's not available, what would you use then?

Dr Myers. Unfortunately, glutaraldehyde-fixed bovine pericardium is our current strategy.

Dr Bacha. I was intrigued by the ostial occlusions that you noticed in those 2 patients. Can you expand a bit on that, where the patch is too long?

Dr Myers. We used our standard described technique for sizing the patches. In these 2 cases, after releasing the crossclamp, we had persistent ventricular fibrillation that was resistant to any form of treatment. In these cases we reclamped the aorta, arrested the heart and explored the extensions, and removed $1 \mathrm{~mm}$ of height from each extension. In each case, the patients were weaned off bypass without any trouble.

Dr Bacha. Was there any echo guidance with this? Could you see that the patch extensions were occluding the ostium?

Dr Myers. Indeed, that was a help in the diagnosis.

Dr Bacha. Some people have recently advocated placing those extension patches at the base of the cusp as opposed to on the free edge of the cusp. In rheumatic fever you have a traction of the free edge, but is that something that could be useful in this particular disease?

Dr Myers. That could be useful. From a technical standpoint, we found it easier to work with the existing cusps, shaving them, if necessary, to make them pliable. But it's true that in our experience, for example, in the PhotoFix pericardium group, the mode of recurrent regurgitation was annular dilation in 1 patient and renewed retraction on the native cusps in 2 patients. One could hypothesize that these 2 patients would not have required a reoperation had they had their own cusps removed entirely and the valve reconstructed completely from the base of the cusps.

Dr Bacha. What about the patient who presents with severe aortic regurgitation and is hemodynamically unstable with active rheumatic fever or unresolved rheumatic fever? Would you recommend the AV repair in that situation?

Dr Myers. It depends entirely on how the tissues appear when we look at the AV. Let's say, ideally, yes. But we can, in those cases, find that the aortic cusps are very friable and that sutures do not hold very well on that. So our strategy would be to attempt a repair; however, it's not always technically feasible.

Dr Bacha. I would be careful with that, because if your rheumatic fever is not burnt out you may have rheumatic fever on the repaired valve.

Dr Myers. On the extended cusps, absolutely.

Dr Gerhard Ziemer (Tuebingen, Germany). Dr Myers, you have to be congratulated for your work and results. And obviously in medicine when you do something and have good results, it's the right thing.

However, I have a conceptual problem with what you're doing and claiming. With the use of fresh autologous pericardium in this position, as you use in MVs, we know that fresh pericardium retracts. So what is the trick or the reason that you replace your cusps with fresh autologous pericardium and it doesn't shrink. Do you use a special size?

I can say in those MVs where I used pericardium and occasionally forgot or glutaraldehyde wasn't there, after 3 months I had some leak because the pericardium was retracting. So why doesn't this happen in your cases?

Dr Myers. In our experience, the mode of failure differs depending on the material, and it's a choice of which is the best available option. Fresh autologous pericardium retracts with time. With glutaraldehyde-fixed pericardium, we found that these rapidly calcify, independently of the length of fixation.

Dr Ziemer. But you did not use autologous glutaraldehydefixed pericardium. You only had bovine, and this is completely different. Did you ever try fresh autologous glutaraldehyde-fixed pericardium?

Dr Myers. We have an initial, very limited experience with that, and we had very rapid calcification in the aortic position, which is why we abandoned that.

Dr Ziemer. Okay. Thank you.

Dr Muhammad Ali Mumtaz (Norfolk, $\mathrm{Va}$ ). I have a couple of comments and 1 question. I'm very curious to see, if you don't have an answer, if the audience or moderators might.

A number of studies, including one from Cleveland Clinic, which I was part of, in which glutaraldehyde-treated pericardium, autologous pericardium, was used, typically there is no early calcification. Late retraction and scarring do happen.

But recently I had the misfortune, or fortune, to use CorMatrix, which is an acellular submucosa of the intestine, in 2 patients. In the second patient, the posterior commissure bicuspid valve dehisced at the attachment. So I had to go back, and thinking I would replace the valve, once I noticed that the commissure had dehisced, I essentially just reattached it. But to my pleasant surprise, just as the company says, the leaflets were entirely replaced by normal tissue. I could not distinguish what was normal and what was not. So I'm curious to know if you have entertained using that? Or if certainly there is no pericardium, why not use CorMatrix (Atlanta, $\mathrm{Ga}$ ), which is acellular or decellularized submucosa of the intestine?

If you don't have experience, I'm just curious to know if the moderators or anybody in the audience has and what have they found in terms of their durability. I've only used it in the last year, and so I really don't have follow-up information.

Dr Myers. I have no experience with the CorMatrix in intracardiac situations, only as an extracardiac material (to minimize pericardial adhesions). But I don't know if one of the moderators has experience with intracardiac use.

Dr Tweddell. I have no experience with it, but I think you've all sort of hit on the point: It's really a materials problem, right? You're able to reconstruct a competent valve at the end of the procedure; it's just trying to find something that will hold up and be as durable as cusp tissue normally is. 
Dr Bacha. I don't have any experience either, but I'm thinking along the same lines as well.

Dr A. Charles Yankah (Berlin, Germany). Why didn't you use anticalcification-treated glutaraldehyde to mitigate calcification?

Dr Myers. That's a good proposition. Unfortunately, it's not freely available in our center. And given our initial experience with fresh autologous pericardium, which was relatively good to the midterm, we continued on that line; but that is indeed a line of thought that could be pursued.

Dr Yankah. Did you make any study on the immune response in the explanted glutaraldehyde, just to identify any tissue reaction, because this could trigger the left ventricular structural valve deterioration and calcification.

Dr Myers. No, we did not. All we did was standard crosssections to get an idea of what was happening in terms of fibrotic reaction, retraction, calcification, and so forth. We have not done any more detailed immunologic research in that line.

Dr Yankah. In view of inflammation of the tissue, did you anticipate or try to treat these patients with anti-inflammatory drugs?

Dr Myers. No, that is not part of our management. Of course, with rheumatic fever or rheumatic heart disease, that is an ongoing process and an issue over time, and that could be another line of further research.

Dr Yankah. Did you put these patients on long-term penicillin to prevent recurrence of rheumatic fever?

Dr Myers. Absolutely.

Dr Andres Jorge Schlichter (Buenos Aires, Argentina). I want to congratulate you on a nice presentation, and I'm not going to ask you anything about the technique because I'm a fan of autologous fresh pericardium.

Where did you get this number of patients with rheumatic fever who are so young in Switzerland? We don't have them in Argentina. We don't have them in underdeveloped countries anymore. An 8-year-old with aortic incompetence due to rheumatic fever is extremely rare. We don't have that in Argentina, and that's an underdeveloped country. There used to be rheumatic fever in Argentina, but not anymore. What we usually observe now is aortic incompetence caused by invasive cardiology (balloon dilation of bicuspid valves). We don't see these tricuspid valves. Did you import these patients?

Dr Myers. Indeed, they were imported. We work with a humanitarian association, and we are a reference center for these patients.

Dr Schlichter. Okay. Excellent answer.

Dr Christian Brizard (Melbourne, Australia). We have used the cusp extension technique in both Paris and Melbourne with autologous pericardium treated with glutaraldehyde. In Melbourne we operate on aboriginal patients, and the incidence of aortic regurgitation in this population is relatively high, but much lower than mitral regurgitation. We have a ratio of 1:10 AV surgery compared with MV surgery.

My question is relevant to the same topic as the previous question. In Paris we operated on patients through the Chain of Hope, or "La Chaine de L'Espoir,', and we received patients from North Africa mostly. It is notoriously difficult to have follow-up information on these patients. We had extensive experience with this technique, and it seemed that at midterm follow-up we had good results. But when you do obtain long-term follow-up of these rheumatic patients, it's not as shiny. Therefore, the current recommendation of the Chain of Hope, when we receive similar patients in France now, is to use mechanical valve replacement rather than cusp extension. The mechanical valve in the aortic position may tolerate antiplatelet therapy in these countries and has good outcome.

Dr Myers. Of course, in a long-term study such as this, the quality of the data is of utmost importance. The humanitarian association with which we are working, Terre Des Hommes, has a system in place that guarantees follow-up with cardiologists, often trained by the association, in northern Africa who can perform the follow-up and get the follow-up data. We are updated yearly with their data and involved in any decisions on reoperations. The long-term follow-up and results in these patients are of utmost importance, especially when offering an option that has a $20 \%$ to $30 \%$ reoperation rate.

Dr Bacha. Thank you, Dr Myers. We're over time, so we're going to have to move on. 